\title{
(8)
}

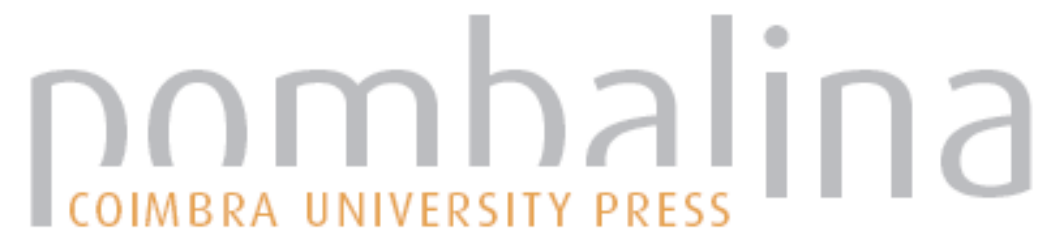

\section{Aggregation of electric current consumption features for extraction of maintenance KPIs}
Autor(es):
Iohansson, Carl-Anders; Simon, Victor; Diego, Galar
Publicado por: Imprensa da Universidade de Coimbra; Faculdade de Ciências e
persistente:
Tecnologia
DOI:
URI:http://hdl.handle.net/10316.2/33360
DOl:http://dx.doi.org/10.14195/978-972-8954-42-0_23
Accessed :
26-Apr-2023 09:40:40

A navegação consulta e descarregamento dos títulos inseridos nas Bibliotecas Digitais UC Digitalis, UC Pombalina e UC Impactum, pressupõem a aceitação plena e sem reservas dos Termos e Condições de Uso destas Bibliotecas Digitais, disponíveis em https://digitalis.uc.pt/pt-pt/termos.

Conforme exposto nos referidos Termos e Condições de Uso, o descarregamento de títulos de acesso restrito requer uma licença válida de autorização devendo o utilizador aceder ao(s) documento(s) a partir de um endereço de IP da instituição detentora da supramencionada licença.

Ao utilizador é apenas permitido o descarregamento para uso pessoal, pelo que o emprego do(s) título(s) descarregado(s) para outro fim, designadamente comercial, carece de autorização do respetivo autor ou editor da obra.

Na medida em que todas as obras da UC Digitalis se encontram protegidas pelo Código do Direito de Autor e Direitos Conexos e demais legislação aplicável, toda a cópia, parcial ou total, deste documento, nos casos em que é legalmente admitida, deverá conter ou fazer-se acompanhar por este aviso.

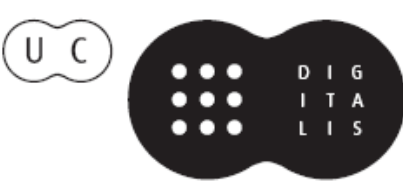




\title{
Aggregation of electric current consumption features for extraction of maintenance KPIs
}

\author{
Carl-Anders Johansson ${ }^{1}$, Victor Simon ${ }^{1}$, Diego Galar ${ }^{1}$ \\ carl-anders.johansson@1tu.se; ${ }^{2}$ victor.simon@1tu.se; ${ }^{3}$ diego.galar@1tu.se \\ ${ }^{1}$ Luleå University of Technology \\ Luleå, Sweden
}

\begin{abstract}
For all electric powered machines there is a possibility of extracting information and calculating Key Performance Indicators (KPIs) from the electric current signal. Depending on the time window, sampling frequency and type of analysis, different indicators from the micro to macro level can be calculated for such aspects as maintenance, production, energy consumption etc.
\end{abstract}

On the micro-level, the indicators are generally used for condition monitoring and diagnostics and are normally based on a short time window and a high sampling frequency. The macro indicators are normally based on a longer time window with a slower sampling frequency and are used as indicators for overall performance, cost or consumption.

The indicators can be calculated directly from the current signal but can also be based on a combination of information from the current signal and operational data like rpm, position etc.

One or several of those indicators can be used for prediction and prognostics of a machine's future behaviour.

This paper uses this technique to calculate indicators for maintenance and energy optimisation in electric powered machines and fleet of machines, especially machine tools.

Keywords - fingerprint, operational data, condition based maintenance (CBM), condition monitoring (CM), energy optimisation, machine tool

\section{INTRODUCTION}

Today's business environment sets ever-higher requirements on reliability, availability and economic performance of plants and equipment. Loss of production due to machine damage, especially if it occurs unexpectedly, diminishes the economic success of an enterprise and must be prevented. In recent years, the emphasis in maintenance has shifted to using emerging technology to measure machinery condition and predict maintenance requirements. Key words like preventive, predictive and condition-based maintenance reflect this tendency. If plant personnel can always make an accurate statement about the condition of their machines and plant assets, they are in the position to plan and introduce appropriate maintenance measures promptly, before larger and more serious damage and associated unplanned machine downtime occur. The bottom line benefits of such an approach, however, can include gaining experience and learning relevant mechanisms or correlations to better control production processes. The key component in this approach is achieving an accurate prediction of failure; therefore, an effective method of monitoring the status of an item or system is essential. Clearly the ideal technique is one in which the condition of the equipment is known at all times and which accurately predicts any potential failure on demand. Condition Monitoring (CM) attempts to fulfil these requirements.

The normal strategy to keep production systems in good condition is to apply preventive maintenance practices, with a supportive workforce being "reactive" in the case of obvious malfunctions, as these have an impact on quality, cost and productivity. The uncertainty of machine reliability at any given time also has an impact. For example, a worn-out mechanism can have higher energy consumption.

The use of intelligent predictive technologies could improve the situation, but these are not widely used in the production environment. Often sensors and monitors needed in the production environment are non-standard and require costly implementation.

Monitoring and profiling the electric current consumption in combination with operating data which describes the way the machine is used (the context) is an easy way to implement Green Condition Based Maintenance (Green CBM) to improve overall business effectiveness. Green CBM takes a triple perspective:

- Maintenance: Optimising maintenance strategies based on the prediction of potential failure, scheduling maintenance operations in convenient periods and avoiding unexpected breakdowns.

- Operation: Managing energy as a production resource and reducing its consumption.

- Product reliability: Providing the machine tool builder with real data about the behaviour of the product and its critical components.

This opens up the possibility of creating new business models for maintenance and service providers.

The Green CBM technique can be applied to many types of machines but we concentrate on machine tools.

This paper is part of the Power Consumption driven Reliability, Operation and Maintenance Optimisation (Power $\mathrm{OM}$ ) project (http://www.power-om.eu/) which is in the 
middle of collecting operating and fingerprint data. The paper is, therefore, mostly conceptual and will concentrate on possible techniques and methods to know and predict the condition of machine tools and fleets of machine tools, especially problems/faults in the spindle drive train and linear axis. The proposed method for Condition Based Maintenance $(\mathrm{CBM})$, based on fingerprint and operating data, gives information about both operating conditions and power consumption without increasing the complexity and can be seen as a Green Condition Based Maintenance platform (Green CBM) [1] for both CBM and energy optimisation.

\section{CONDITION MONITORING OF MACHINE TOOLS}

Knowing and predicting the condition of an asset is valuable. During the last 40 years, numerous diagnostic techniques have been developed, many based on signal analysis and statistical methods.

For stationary operating conditions, even prognostics of the failure work well, but the methods used often require costly installation of transducers and signal analysis equipment handled by skilled personnel.

For some time, there has been increasing interest in methods based on available operating data that do not require costly equipment or skilled personnel.

This is especially relevant for those with a fleet of similar equipment where methods and experience can be reused, for example, producers and owners of windmills, airplanes, ships, cars \& trucks, elevators, packing machines and machine tools.

Machine spindle defects are responsible for frequent and cost-intensive downtimes in machine-tools, so normally those are a focus of condition monitoring. But a machine tool consists of many subsystems that also can be supervised.

In the Power OM project, we have concentrated on the spindle and the linear axis.

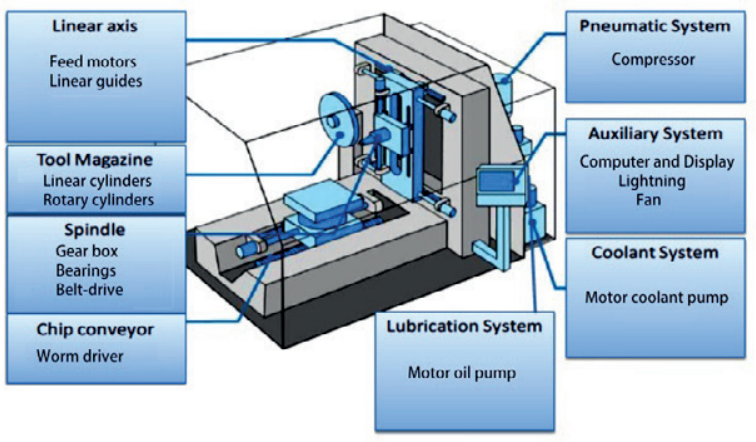

Figure I. Main sub system of a CNC Machine (source Siemens)

The main technique for detecting mechanical and electrical problems uses vibration analysis or Motor Current Signature Analysis (MCSA) in combination with context data. In the Power OM project, we use both, but in this paper we will concentrate on MCSA in combination with context data. MCSA uses the electric motor as a transducer, allowing the user to evaluate the electrical and mechanical condition of the motor control and, by extension, of the machine. The basic idea is that any load or speed variation within an electromechanical system produces correlated variations in current and voltage. The resulting time and frequency signatures reflect loads, stresses, and wear throughout the system, but seeing these requires a mapping process or pattern recognition. Comparing a reference, electric signature of equipment in good condition (the fingerprint), and equipment under monitoring supports fault identification.

There are a number of commercial products in this area, including the ARTESIS system (www.artesis.com). The methods described in this paper are similar to those used in other systems but are more focused on other context data than is available in current, voltage and vibration signals.

Power monitoring as torque sensor is evaluated in [2]. Other work uses power analysis to detect production machine failures using current signals [3,4] and machine internal signals [5].

As we can see in $[6,7]$ several failures can be detected using induction motor current analysis. The controlled values, for example of a gearbox failure, can be compared in the stator current spectrum, because there are several peaks related to shaft and gear speed. Characteristic gearbox frequencies can be detected in the stator current spectrum.
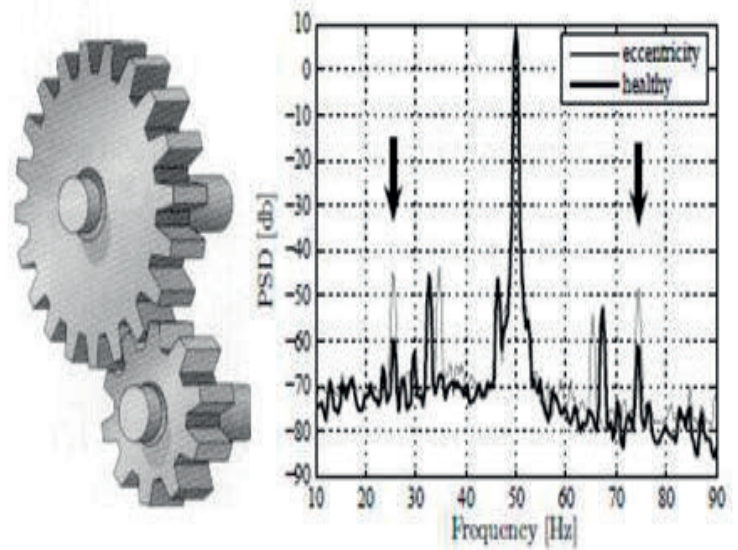

Figure II. Gear Failure detection with current signal

Current based diagnosis of mechanical faults such as unbalance and misalignment can be performed in the same way. It is possible to control the rotating movement of the machine; in addition, some work has been done on linear movement. For example, Electro Mechanical Actuators (EMA) are widely used in aeronautic systems; the use of Health Monitoring is also widespread [8, 9, 10]. Similar actuators are used in machine tools.

\section{A. Data collecting}

The proposed method uses two types of input data: fingerprint data and operating data.

\section{1) Fingerprint data}

Fingerprint data are collected in a standardised way every day/week/month using a test procedure. As part of this 
standardised procedure, the machine runs a special $\mathrm{CNC}$ programme every time the fingerprint is collected.

There is also a possibility of using standard sequences in ordinary production programmes like tool changing for part of the fingerprint collection.

The data are collected with a sampling frequency between $100 \mathrm{~Hz}$ and $50 \mathrm{kHz}$, depending on the type of data.

Typical data collected and synchronised in time are:

- Vibration

- Motor power for spindle and linear axis (current signal and motor current signature analysis)

- $\quad$ RPM and speed for spindle and linear axis and axis position

The data can be analysed in both time and frequency domains [11] and a number of features (Table II.1) can be calculated for each signal. In the frequency domain, the system follows the vibration levels on known frequencies like gear mesh frequencies, bearing frequencies, rotational speed etc. and their harmonics.

For faults/problems in the gear train, such as the bearing and gear problem, the most sensitive features have been chosen through the use of a test bench (see figure II.3) where different types of faults can be simulated and by using faulty components sent in by customers for repair (see figure II.4).

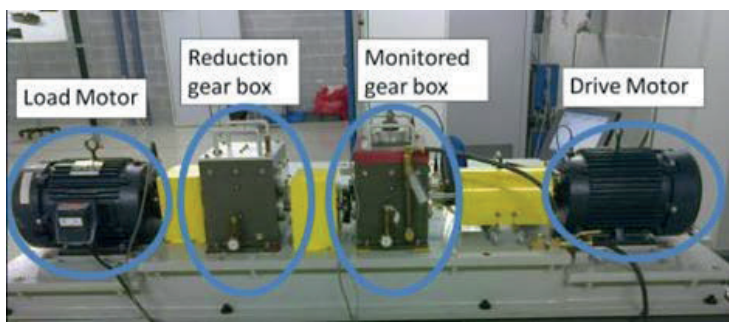

Figure III. Test bench for gear train

TABLE II.1 Time domain features

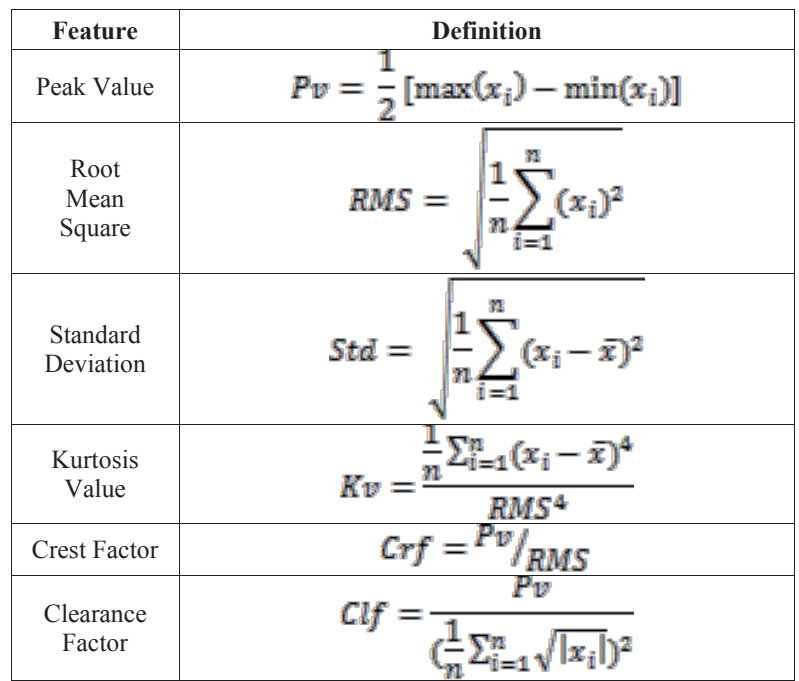

\begin{tabular}{|c|c|}
\hline $\begin{array}{c}\text { Impulse } \\
\text { Factor }\end{array}$ & $\operatorname{Im} f=\frac{P V}{\frac{1}{n} \sum_{i=1}^{n}\left|x_{i}\right|}$ \\
\hline $\begin{array}{c}\text { Shape } \\
\text { Factor }\end{array}$ & $S h f=\frac{R M S}{\frac{1}{n} \sum_{i=1}^{n}\left|x_{i}\right|}$ \\
\hline $\begin{array}{c}\text { Normal } \\
\text { Negative } \\
\text { value } \\
\text { valihood }\end{array}$ & $N N L=-\ln L_{p} L=\prod_{i=1}^{N} f\left(x_{i}, \mu, \sigma\right)$ \\
\hline
\end{tabular}

Normally, the spindle rotates clockwise. In some operations, like threading and some milling, it operates counter clockwise. The latter operation normally has less power/torque. Therefore, comparing the difference in feature values in different rotational directions gives valuable information.

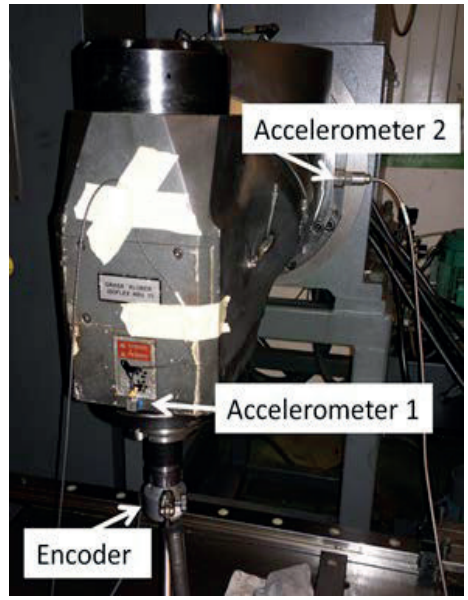

Figure IV. Spindle head in test bench

Table 2 shows the testing of a spindle head before and after repair in both rotational directions. As the table shows, the degradation was greater in the 'normal operation' direction (clockwise).

TABLE II.2 Motor Current Analysis of the Spindle Motor showing the difference in behaviour for a spindle head rotating in different directions. $\mathrm{CCW}$ is the normal rotating direction

\begin{tabular}{|c|c|c|c|}
\hline \multirow{2}{*}{ Feature } & Value & $\begin{array}{c}\text { Rotational } \\
\text { direction }\end{array}$ & Spindle Status \\
\hline \multirow{4}{*}{ Crest Factor } & 1,96 & Counter clockwise & Repaired \\
\cline { 2 - 4 } & 2,24 & Counter clockwise & Faulty \\
\cline { 2 - 4 } & 1,96 & Clockwise & Repaired \\
\cline { 2 - 4 } & 1,96 & Clockwise & Faulty \\
\hline \multirow{3}{*}{$\begin{array}{c}\text { Rotational } \\
\text { Frequency } \\
\text { sideband }\end{array}$} & 3,56 & Counter clockwise & Repaired \\
\cline { 2 - 4 } & 12,7 & Counter clockwise & Faulty \\
\cline { 2 - 4 } & 4,73 & Clockwise & Repaired \\
\cline { 2 - 4 } & 4,64 & Clockwise & Faulty \\
\hline
\end{tabular}

For the linear axis, there can be problems with the drive train (motor/gearbox/ball screw/nut/rack/pinion) and the linear bearings (see figure II.5). 


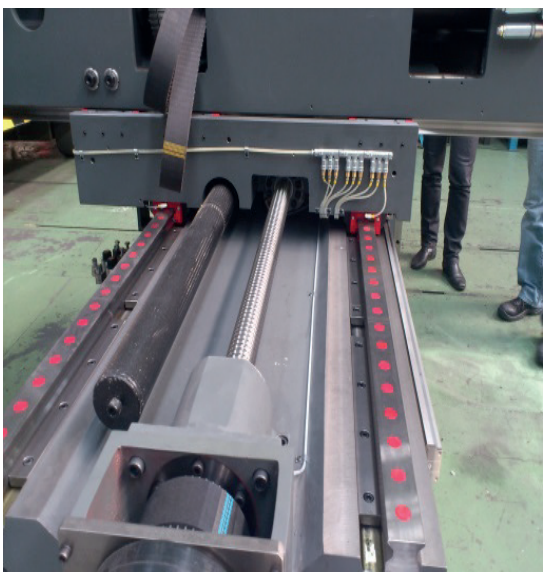

Figure V. Linear guides ball screw/nut

For the drive train, the machine tool axis dynamics is an important factor; it can be analysed by looking at the position/speed/acceleration and jerk values and by comparing differences in commanded and actual position [12].

With high resolution power or vibration measurements on the linear axis, it is possible to isolate problems in ball screw/nut, rack/pinion, hydraulic counter balance system, linear bearings [13].

\section{2) Operating data}

Operating data are collected with a sampling frequency between 1-100 Hz. The data are collected via interfacing with the Computer Numerical Control (CNC) controller of the Machine Tool (see figure II.6). In the case of the Power-OM project, the research toolbox GEM OA (Open Architecture) hardware from Artis is used for the data collection [14].

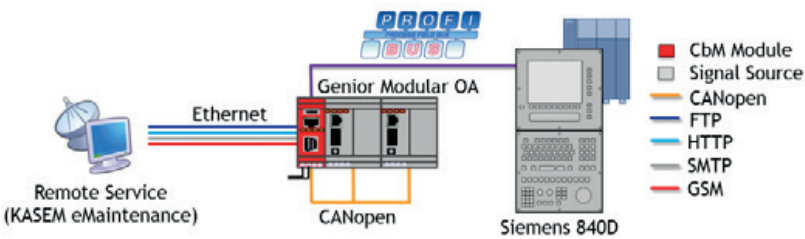

Figure VI. Local data collection unit GEM OA (Artis)

Typical data collected are:

- Spindle power and rpm

- Motor power and position for linear axis

- Difference between commanded and actual position

- Temperatures

- Programme number

- Tool number

- Alarms (sampled from the CNC or taken from the log file)

The operating data describe the way the machine has been used between the fingerprints.

3) KPI calculation
From the operating data, a number of KPIs can be calculated, for both condition monitoring and energy optimisation. Some examples are:

- Number of starts/stops/accelerations/retardations

- Total travelled length for linear axis and distribution over the axis or 'travelled load' calculated from power need during acceleration of the axis

- Mean power/torque for spindle and axis and distribution over the axis

- Difference in behaviour in different rotational directions for both spindle and linear axis

- $\quad$ Running time in different rpm, direction and power intervals

- Number of alarms per type/group

- Total energy used for a certain product/programme in a certain machine

- Total energy used for a certain tool

For each machine/component in the fleet, typical faults/problems are identified, and the most sensitive fingerprint features and KPIs are chosen for each. This means each machine/component has a number of faults, and each fault has a number of features and KPIs that can be traced in a multi-dimensional space to estimate the condition of the machine/component. The threshold for the estimation is based on the results of tests with known faults using a test bench, tests of faulty components (so far only for repaired and faulty spindle head) and the experience of this or similar machines in the fleet.

To begin, the estimation can be based on the history of the machine tool, including:

- Age of component/machine tool

- Designed lifetime of component/machine tool

- Type of production/use $(8 \mathrm{~h} / 24 \mathrm{~h} / 7 \mathrm{~d}$, heavy, medium, low)

- Maintenance history

- Experience of similar machines in the fleet

After a while, however, the estimation can be based on results from fingerprint and operating data.

The change in value of the different features between two fingerprints indicates the degradation of the component; it depends on both the previous condition and the way the machine has been used.

This means that the future condition, the feature value $F_{n}$, is a function of previous condition value $F_{n-1}$ and subsequent operating data.

$$
F_{\mathrm{n}}=f\left(F_{\mathrm{n}-1} \text {, Operational data }\right)
$$

\section{ENERGY OPTIMISATION}

A recent Directive of the European Parliament on Energy using Products [Directive 2009/125/EC] establishes a framework for the eco-design requirements of energy-using products. The European Commission has published a working plan [Working plan for 2009-2011 under the Eco design Directive] with a list of energy-using product groups which 
can be considered prioritised. Machine tools is included as one of ten product groups.

As a result, the machine tool sector is beginning to change. An example is the German Machine Tool Builder Association (VDW) which has developed the label Blue Competence.

In short, energy saving measures are increasingly relevant, especially in the machine tool sector for metal working production, as this sector requires $15 \%$ of the entire electric power consumption (German statistics).

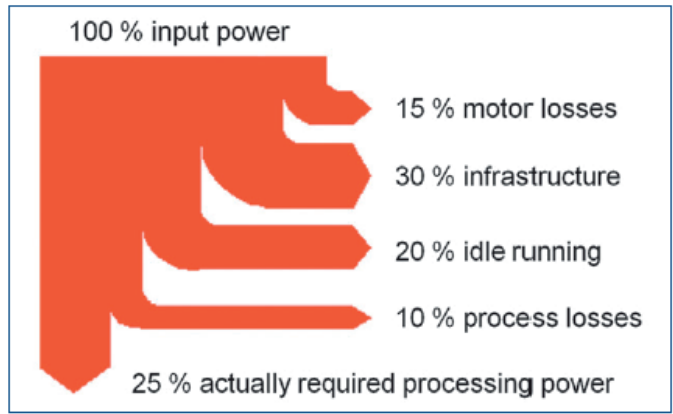

Figure VII. Machine tool power flow diagram (Translated from [15])

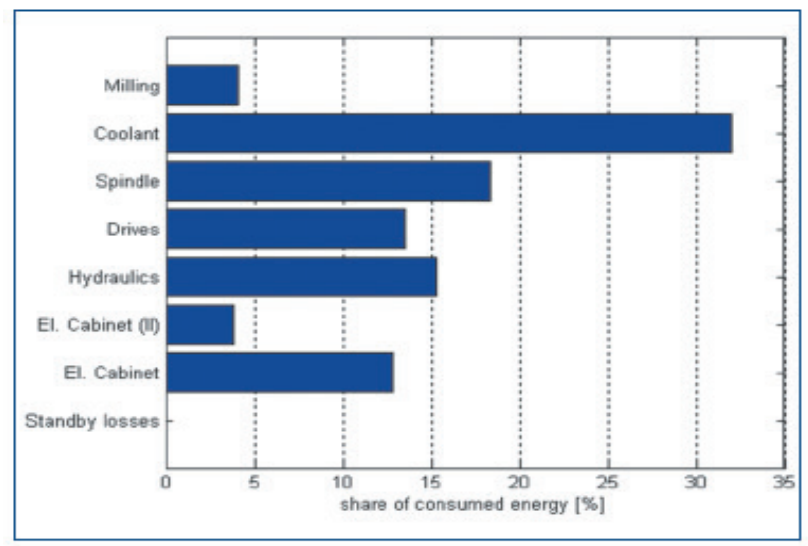

Figure VIII. Share of energy consumed by each Machine Tool component

Figures III.1 and Figure III.2, extracted from an ISW study [16] show with more detail where energy is lost in the use of a machine tool and the share of energy consumed by each main component of the machine tool. Motor losses and idle running comprise $35 \%$ of the energy loss, while spindle and drives consume more than $30 \%$.

Power optimisation in machine tools is normally in one of the following categories:

- Limiting power output by optimising production planning

- $\quad$ Minimising the use of energy by putting subsystems like cooling fluid, hydraulic pumps, cooling fans etc. into idle/sleep mode

- Minimising the use of energy by optimising cncprogrammes and processing paths.
- Reducing power consumption for deep whole machining with an adaptive pecking cycle, which executes pecking as needed by sensing cutting load.

- Reducing power consumption by synchronising the spindle acceleration/ deceleration with the feed system at rapid traverse stage.

- Minimising the use of energy by cutting parameters and optimising tool selection.

- Reducing power consumption for drilling and face/end milling by setting the cutting conditions high yet within a value range which does not compromise tool life and surface finish, thereby shortening machining time

- Minimising the cost for energy by optimising production planning based on different energy prices at different time of the day

The energy efficiency ( $n$ ) of a machine tool operation can be calculated in different ways.

$\frac{\text { Spindle used Energy }}{\text { Total Energy }} \quad$ (2) or as $\frac{\text { Total Energy }}{\text { RMV }}$

where RMV= Removed Material Volume [cm3]

\section{CONCLUSION}

The analysis of data from existing sensors and information about a machine's power consumption and operating conditions permits the use of a new, easy to implement, Green Condition based Maintenance platform (Green CBM).

For each machine/component in the fleet, typical faults/problems are identified, and the most sensitive fingerprint features and KPIs are calculated for each.

The calculation is based on data extracted from the electric current signal through MCSA in combination with context data.

Green CBM does not increase the complexity and can be used for many types of manufacturing machines.

By integrating all the information from machines, the fleet of machines and even between companies, the Green CBM platform can act as a hub of technology, providing the different user profiles (Machine Tool users, Maintenance Service Providers and Machine Tool Manufacturers) with services for Maintenance and Energy Optimisation and increased machine Reliability.

\section{ACKNOWLEDGMENT}

The research has received funding from the European Community's Framework Programme FP7-2012-NMP-ICTFoF.

Work programme: FoF.NMP.2012-2 "Methodologies and tools for the sustainable, predictive maintenance of production equipment" under grant agreement no. "314548 - Power-OM". The Consortium consists of TEKNIKER, ARTIS, FAGOR AOTEK, PREDICT, MONITION, GORATU and Luleå University of Technology (LTU). 


\section{REFERENCES}

[1] C-A. Johansson, D. Galar, R. Villarejo, M. Monnin, "Green Condition based Maintenance - an integrated system approach for health assessment and energy optimization of manufacturing machines", The Tenth International Conference on Condition Monitoring and Machinery Failure Prevention Technologies, Krakow, Poland, 18-20 June 2013.

[2] J.L. Stein, Wang and Churn-Hway, "Analysis of Power Monitoring on AC Induction Drive Systems", Journal of Dynamic Systems, Measurement, and Control - June - Volume 112, Issue 2, 239, 1990

[3] F. Zhao, X. Mei, T. Tao, G. Jiang, and Y. Zhou, "Fault diagnosis of a machine tool rotary axis based on a motor current test and the ensemble empirical mode decomposition method", Journal of Mechanical Engineering Science vol. 225, May 2011

[4] K. Chinmaya, A.R. Mohanty, "Vibration and current transient monitoring for gearbox fault detection using multiresolution Fourier transform", 2008

[5] M. Abu Ali, J. Lee, and W. Zhao, "Methods and Systems for Energy Prognosis", United States Patent Application Publication No US 2011/0066391 A1, Mar-17-2011

[6] E. L. Bonaldi, L. E. L. Oliveira, J. G. Borges da Silva, G. LambertTorres, and L. E. Borges da Silva, "Detecting Load Failures using the Induction Motor as a Transducer", 10 th International Conference on Control, Automation, Robotics and Vision; Hanoi, Vietnam 2008 pp 196-199. 2008

[7] H. B. Attia, "Détection et localisation de défauts mécaniques d'un entraînement électrique à vitesse variable" Ph.D. thesis, Institut National Polytechnique de Toulouse, Toulouse, France, Mar. 2003.

[8] S. Curran, T. E. Walters, and A. J. Chirico "Health monitoring and prognostics for electro mechanical actuation", Proceedings of the International Conference on Recent Advances in Aerospace Actuation Systems and Components, pp. 47-55. 2010
[9] C. S. Byington, M. Watson, and D. Edwards, "Data-driven neural network methodology to remaining life predictions for aircraft actuator components", Proc. IEEE Aerospace conference, 6, pp. 3581-3589, 2004.

[10] E. Balaban, P. Bansal, P. Stoelting, A. Saxena, K. F. Goebel, and S. Curran, "A diagnostic approach for electromechanical actuators in aerospace systems", Proc. IEEE Aerospace conference, pp. 113, 2009.

[11] D. Galar, U. Kumar, J. Lee \& W. Zhao,"Remaining Useful Life Estimation using Time Trajectory Tracking and Support Vector Machines", 25th International Congress on Condition Monitoring and Diagnostic Engineering, Conference Series 364 (2012) 012063, Huddersfield, United Kingdom, 18-20 June 2012. doi: 10.1088/1742-6596/364/1/012063

[12] J.J. Santiago-Pérez,R.A. Osornio-Rios \& R.J. Romero-Troncoso, G. Herrera-Ruiz \& M. Delgado-Rosas, "DSP algorithm for the extraction of dynamics parameters in $\mathrm{CNC}$ machine tool servomechanisms from an optical incremental encoder", International Journal of Machine Tools \& Manufacture 48 (2008) (1318-1334).

[13] B. Huang, H. Gao, X. Mingheng, X. Wu, M. Zhao \& L. Guo, "Life Prediction of CNC Linear Rolling Guide Based on DFNN Performance Degradation Model", Seventh International Conference on Fuzzy Systems and Knowledge Discovery (FSKD 2010), Yantai, China, 10-12 August 2010.

[14] A. Alzaga, E. Konde, I. Bravo, R. Arana, A. Prado, C. Yurre, M. Monnin, G. Medina-Oliva, "New technologies to optimize", EuroMaintenance conference, Helsinki, Finland, 5-8 May 2014.

[15] [http://www.energie.ch/themen/industrie/infel/druckluft.htm][2014 $-07-31]$

[16] B.V. Dasarathy, "Information Fusion. What, Where, Why, When, and How? Information Fusion”, 2, pp75-76, 2001 